\title{
RETRACTION
}

\section{ON A WEAKLY UNIFORMLY ROTUND DUAL OF A BANACH SPACE - RETRACTION}

\section{J. R. GILES}

doi:10.1017/S0004972712000597, Published by The Australian Mathematical Society, 1 August 2012

The argument in [1] claiming a renorming of a Banach space with separable second dual to have WUR dual is built upon a false application of Goldstine's Theorem. The author, having noticed this gap in the proof, has retracted the article.

\section{Reference}

[1] J. R. Giles, 2012 'On a weakly uniformly rotund dual of a Banach space'. Bull. Aust. Math. Soc. doi:10.1017/S0004972712000597. 